\title{
Livro didático: seu papel nas aulas de acentuação gráfica
}

\section{The role of the school textbook in lessons on word written accents}

\author{
Kelly Priscilla Lóddo Cezar* \\ Geiva Carolina Calsa** \\ Edson Carlos Romualdo***
}

\section{RESUMO}

O presente artigo tem como objetivo apresentar os resultados de uma investigação sobre o uso do livro didático na prática pedagógica de dois professores - um de 4. e e outro de 5 . "séries do ensino fundamental - sobre os conteúdos de acentuação gráfica e tonicidade. Considerou-se como hipótese da pesquisa que os professores continuam vinculados a uma abordagem pedagógica algorítmica e mnemônica, embora estudos anteriores mostrem que este tipo de ensino não seja o mais adequado para a aprendizagem da língua falada e da língua escrita. Para o desenvolvimento do estudo realizaram-se observações de aulas sobre os conteúdos investigados e análise dos livros didáticos utilizados pelos professores. As observações evidenciaram privilegiamento do uso do livro didático e tempo reduzido para exposição desses conteúdos, enquanto os livros didáticos mostraram não diferenciar os dois aspectos linguísticos (fala e escrita), priorizando o ensino de acentuação gráfica por meio da visualização e memorização de vocábulos acentuados graficamente. Nos dois casos, constatou-se confusão conceitual: não há clareza de que a sílaba tônica refere-se a aspectos da fala, enquanto a acentuação gráfica está diretamente vinculada à escrita. Os dados sugerem que a acentuação gráfica pode ser ensinada como um algoritmo gramatical desde que acompanhado de um processo de tomada de consciência dos conceitos envolvidos nas normas gramaticais.

Palavras-chave: educação; tonicidade; acentuação gráfica; formação de professores; livro didático.

* Mestre em Letras pela Universidade Estadual de Maringá. Maringá-PR.

** Professora do Departamento de Teoria e Prática da Educação e do Programa de Pós-Graduação em Educação da Universidade Estadual de Maringá. Doutora em Educação/UNICAMP.

*** Professor do Departamento de Letras e do Programa de Pós-Graduação em Letras da Universidade Estadual de Maringá. Doutor em Letras/UNESP. 


\begin{abstract}
This paper aims at presenting the results of an investigation on the use of the textbook, particularly on word written accents and tonicity, in the pedagogical practice of two $4^{\text {th }}$ and $5^{\text {th }}$ grades primary school teachers. Although several studies have shown that the algorithmic and memorizing pedagogical approach is not adequate in the learning of spoken and written language, there is still the supposition that teachers are still linked to the above. Lesson reports on the contents mentioned above and school textbook analyses were undertaken. Reports showed that there was a paramount importance given to the use of textbooks, that short time was allowed for the exposition of contents and that the textbooks failed to distinguish between the two linguistic modes (spoken and written). In fact, the teaching of word written accents by viewing and memorizing accented words is priority. A conceptual confusion exists in both cases since the tonic syllable is an aspect of speech whilst word written accent is directly bound to writing. Data suggests that, as an aspect of grammar rules, word written accent should be taught as a grammatical algorithm within a process of grammar norms.

Keywords: education; tonicity; word written accent; teachers' training; school textbook.
\end{abstract}

\title{
Introdução
}

Com a difusão da "Pedagogia Tecnicista" no sistema educacional brasileiro, a partir da década de 1970, o uso do livro didático sofreu alterações quanto aos conceitos e a forma como passaram a ser apresentados. Anteriormente a esta fase, os materiais didáticos - As Antologias - desempenhavam o papel de auxílio das aulas. O caráter auxiliar dos materiais didáticos, depois da década de 1960, foi praticamente extinto e substituído por um papel de destaque. Em razão das necessidades econômicas e sociais da industrialização, o ensino deixou de ter uma preocupação essencialmente conceitual, enquanto a rapidez e a praticidade tornaram-se seu enfoque e levaram os livros didáticos a uma posição de direcionamento e orientação do trabalho escolar. O professor assumiu o "segundo plano" no processo ensino-aprendizagem e o livro passou a ocupar o "primeiro plano". Em lugar do material didático, o professor se transformou em auxiliar das atividades didáticas favorecendo a leitura e a realização de exercício dos livros didáticos cujo uso tornou-se obrigatório no sistema educacional brasileiro. 
A imagem do professor foi diretamente atingida, pois ser professor deixou de significar domínio de conhecimento e passou a representar submissão às instruções do livro didático. Essa mudança provocou a dependência do professor e até dos alunos em relação ao uso do material didático. De acordo com Machado (1996), a dependência da escola em relação aos livros didáticos vem acarretando o rebaixamento da qualidade dos conteúdos ministrados na disciplina de Língua Portuguesa. Ao encontro dessa posição, os dados das avaliações oficiais (SAEB/INEP, 2002) mostram que os alunos do ensino fundamental e médio vêm apresentando defasagem crescente, cerca de dois a três anos de atraso entre a série em que se encontram e os conhecimentos que deveriam dominar, na aprendizagem de língua portuguesa. Para Batista (1997) e Travaglia (1996), o desempenho insatisfatório dos alunos pode ser explicado pela ineficiência das metodologias de ensino de Língua Portuguesa que vêm sendo utilizadas pelas escolas. Particularmente em relação ao ensino de gramática, os Parâmetros Curriculares Nacionais (BRASIL, 1998) assinalam a existência de graves lacunas teóricas e práticas.

Cezar, Romualdo e Calsa (2006) observam que o desempenho insatisfatório dos alunos é decorrente também da falta de compreensão sobre a necessidade de aprendizagem da língua portuguesa por parte dos falantes nativos do português. É comum os alunos questionarem o porquê e para quê são obrigados a frequentar esta disciplina com uma carga horária equivalente a outras, como a matemática, considerada mais importante para sua formação escolar. Para muitos, a aprendizagem formal da língua portuguesa não tem um significado concreto e útil, porque a linguagem formal é utilizada apenas no ambiente escolar (escrito) ou em situações muito especiais (palestras, apresentações, concursos, entre outros) com as quais não se identificam. Esse comportamento sugere não compreenderem a função de cada uma das variedades e modalidades linguísticas, como a oral e a escrita, tanto em seu registro coloquial como o culto ou padrão. Segundo a literatura (TRAVAGLIA, 1996; CALSA, 2002; CAGLIARI, 2002), a escola tem ensinado conceitos gramaticais incompletos, imprecisos e, às vezes, incorretos que não promovem reflexão sobre a importância dessa aprendizagem para a formação ampla e diversificada desses indivíduos em relação à língua portuguesa.

Frente às considerações sobre as defasagens existentes no processo de aprendizagem da língua portuguesa, este artigo tem por objetivo identificar os procedimentos utilizados por dois professores - um de final do primeiro ciclo e outro de início do segundo ciclo fundamental - de uma escola pública central do município de Maringá-PR, no ensino de um conteúdo de gramática. Buscou-se verificar o uso do livro didático em sala de aula no ensino de acentuação gráfica, um tema que tem gerado confusão conceitual dos alunos por envolver conceitos 
e procedimentos geralmente ensinados sem a necessária distinção do conceito de tonicidade. Não ensinados adequadamente, esses conteúdos além de gerar confusão conceitual favorecem a instalação de obstáculos epistemológicos que dificultam ou impedem aprendizagens posteriores.

\section{Uso do livro didático no ensino de gramática}

Na década de 1960, como afirma Berger (1976), o sistema educacional brasileiro passou a ser fortemente atrelado ao sistema político do país. Com a ascensão dos militares foi introduzida a vertente pedagógica Tecnicista, de origem norte-americana. Esta modalidade de ensino foi ao encontro da necessidade de escolarização rápida e técnica dos trabalhadores que precisavam qualificar-se como mão-de-obra industrial.

Segundo Ghiraldelli (1991) e Munakata (1996 apud SILVA, 1998), os objetivos da Pedagogia Tecnicista foram atingidos com maior precisão por meio do uso dos livros didáticos que, nesse período, tiveram seu espaço escolar ampliado ao se tornarem obrigatórios. Em decorrência disso, em pouco tempo os professores deixaram de ser considerados a principal fonte de saber e planejamento e passaram a basear sua atuação didática nesses manuais. Com essa nova modalidade de ensino, o professor deixou de ser um educador autônomo para tornar-se um mero instrutor.

Para Soares (2001), a maior demanda de alunos no ensino fundamental e médio, a qualificação ligeira dos professores, e a redução salarial que levou muitos a buscarem métodos de ensino menos exigentes em termos de dedicação profissional acabou por provocar o uso intensivo do livro didático. Consolidou-se então uma tradição de uso do livro didático no sistema educacional brasileiro, e uma crescente dependência do professor em relação a esses manuais. A fidelidade a esses materiais, de acordo com Silva (1996, p. 12), vem provocando uma espécie de "anemia cognitiva" nos professores, pois segui-los representa alimentar e cristalizar "um conjunto de rotinas altamente prejudiciais ao processo educacional do professorado e do alunado". Essa dependência está diretamente relacionada à má qualidade da formação do professor e sua superação exige políticas educacionais que promovam a autonomia conceitual e didática desses profissionais. Para o autor, os livros didáticos devem informar, orientar e instruir o processo de ensino-aprendizagem e não impor uma forma de ensinar ao professor.

Em assentimento com o pensamento do autor, Lajolo (1996) lembra que 
os livros didáticos desempenham um papel fundamental na educação escolar, pois, dentre os outros elementos que compõem o processo ensino-aprendizagem, parece ser o de maior influência sobre as decisões e ações do professor. De acordo com a autora, no Brasil, a adoção do livro didático continua tendo como finalidade determinar os conteúdos e procedimentos de ensino tendo em vista as lacunas existentes na formação do professor e na organização do sistema educacional. Como consequência, para fugir do uso inadequado do livro didático, o professor deve avaliar sua qualidade e abordagem conceitual, pois nem sempre o referencial teórico corresponde aos conteúdos e exercícios presentes nesses manuais. Além disso, devem ser observadas suas incoerências, erros e conceitos incompletos.

Lajolo (1996, p. 8) lembra, contudo, que a má qualidade conceitual e técnica do livro pode se transformar em um material didático satisfatório a partir da identificação e discussão de seus erros com os alunos. Para ela "não há livro que seja à prova de professor: o pior livro pode ficar bom na sala de um bom professor e o melhor livro desanda na sala de um mau professor. Pois o melhor livro [...], é apenas um livro, instrumento auxiliar da aprendizagem". Nenhum livro didático, por melhor que seja, pode ser utilizado sem adaptações. Machado (1996) também chama a atenção para o fato de que mais importante que a qualidade do material didático é a formação do professor, pois ele precisa estar preparado para o desenvolvimento de um ensino qualificado, que inclui a análise dos livros didáticos adotados pela instituição escolar.

Em um estudo sobre os livros didáticos utilizados no sistema educacional brasileiro, Machado (1996) constatou que, além da falta de regularidade de sua atualização que tem provocado a baixa qualidade de seus conteúdos, apresentam custo demasiadamente alto para o padrão de consumo da maioria da população. $\mathrm{O}$ autor assinala que a melhoria da qualidade dos livros didáticos depende do estímulo dos órgãos governamentais e de uma maior qualificação dos professores. Neste caso, é imprescindível o desenvolvimento da capacidade crítica dos acadêmicos dos cursos de Pedagogia e das Licenciaturas das diversas áreas de conhecimento em relação ao papel dos livros didáticos no ensino escolar.

Para Pozo (1999), Arnay (1999) e Lacasa (1999), a fragmentação dos conceitos nos manuais didáticos transmite aos alunos uma noção de "falsa ciência", e não os introduz na "cultura científica escolar", função social específica dessa instituição. Segundo Machado (1996, p. 35), a "excessiva subdivisão dos temas" dos livros didáticos em doses correspondentes à duração de uma hora-aula (50 min.) também corrobora para a fragmentação dos conceitos científicos a ponto de, em alguns casos, tornarem-se irreconhecíveis. 


\section{Tonicidade e acentuação gráfica}

A capacidade de se comunicar e se expressar por meio da fala é inerente ao ser humano e a esta capacidade dá-se o nome de linguagem. Para realizá-la, utiliza-se o sistema denominado língua. Sabe-se, pelos estudos realizados por Saussure (1990), que a língua é um fato social, é exterior ao indivíduo, convencional, pertencente a uma comunidade linguística. Ao usá-la individualmente, o falante concretiza, por exclusão, as possibilidades que ela oferece, no ato de fala. Ao se comunicar, o falante faz uso da estrutura psíquica denominada pelo estudioso de signo linguístico, que é composto de um conceito, o significado, e uma imagem acústica, o significante. Ambos ocorrem simultaneamente no ato da fala.

Os sinais físicos que se produzem na fala são os sons - os fonemas - que podem realizar-se de maneiras variadas. Para Câmara Jr. (2002, p. 118), o fonema é um "conjunto de articulações dos órgãos fonadores cujo efeito acústico estrutura formas lingüísticas e constitui numa enunciação o mínimo segmento distinto". Os fonemas são unidades abstratas mínimas, indivisíveis e distintivas da língua. São abstratas por serem os tipos ideais de sons constantes do sistema língua, as possibilidades dos falantes e não a sua concretização. São indivisíveis uma vez que não podem ser separadas em unidades menores.

Além dos aspectos segmentais da fala (linearidade dos signos linguísticos), a comunicação envolve elementos suprassegmentais: os acentos e tons da língua. Os acentos manifestam-se pela altura, intensidade e duração de um vocábulo, consideradas suas propriedades acústicas. Os tons estão relacionados à altura do som. Apesar da língua portuguesa não usar os tons como elementos diferenciadores do léxico, em alguns casos os aspectos suprassegmentais são importantes para a distinção e significação de um vocábulo.

Em língua portuguesa, a tonicidade está vinculada às suas origens grecolatinas. A língua latina teve um enriquecimento gramatical ao entrar em contato com o alfabeto e as regras gramaticais gregas. Contudo, não incorporou os acentos gráficos gregos como marca de tonicidade. A gramática latina marca a acentuação das palavras pela intensidade da sílaba entre breve e longa. Em latim não há palavras oxítonas, portanto, todos os dissílabos são paroxítonos. A sílaba tônica é sempre a penúltima ou antepenúltima. De acordo com Câmara Jr. (2002), os latinos não seguiram os moldes de acentuação gráfica grega em razão de, em língua latina, suas regras serem demasiadamente simples. As línguas modernas de origem latina seguem, basicamente, as regras e nomenclaturas herdadas pelos romanos dos gregos. Portanto, ao se estudar tais línguas, são 
encontrados termos já usados pelos gregos, como acento agudo, acento circunflexo, prosódia, entre outros.

A definição de sílaba tem sido um dos problemas encontrados nos estudos fonéticos. Há, entre os estudiosos, diversidade de critérios para a análise silábica. Drucksilbe (apud CÂMARA JR., 1970) define sílaba como sendo a emissão do ar por impulso, em que cada um corresponde a uma sílaba, dinâmica ou expiratória. Um segundo critério é o da energia de emissão que corresponde a maior energia de emissão, ou acento silábico, durante a articulação de uma sílaba. Por fim, Brücke (apud CÂMARA JR., 1970, p. 70) conceitua sílaba a partir de seu efeito auditivo, isto é, pela variação da perceptibilidade em uma enunciação contínua. Denomina a sílaba de sonora por observar "que a enunciação, sob o aspecto acústico, se decompõe espontaneamente em segmentos, ou sílabas, assinalados por um ponto máximo de perceptibilidade $[\ldots . .$. ".

Independente do critério utilizado, a conceituação de sílaba sempre envolve o ápice silábico que, pelos apontamentos de Borba $(1975$, p. 52), corresponde à tensão máxima a que se chega ao pronunciá-la. Para o autor, a sílaba se compõe de "uma tensão crescente e uma tensão decrescente. A primeira parte da sílaba é crescente até chegar à tensão máxima [...], a partir da qual começa a tensão decrescente". O ápice silábico, normalmente, é uma vogal. Câmara Jr. (2002) destaca que a vogal sempre é o ponto de maior tensão da sílaba. No caso dos ditongos haverá sempre uma vogal como ápice, sendo a outra denominada semivogal.

Quando formados por mais de uma sílaba, os vocábulos sempre têm uma delas pronunciada de forma mais intensa, contraponto à sílaba átona, que é pronunciada de forma mais branda. Identificar a sílaba tônica dos vocábulos formais é uma das grandes dificuldades encontradas no processo de aprendizagem escolar, em especial, na fase de alfabetização.

Para Cagliari (2002), esse problema surge principalmente pelo fato de a escola não apresentar a tonicidade das palavras como uma ocorrência da pronunciação e não da escrita. A tonicidade é identificada nas palavras somente quando alguém busca verificar a posição em que se encontra a sílaba tônica. O autor assinala que, durante o processo de alfabetização, a escola não deve abordar a diferenciação das sílabas átonas e tônicas a partir de seu conceito. Ele acredita que elas devem ser estudadas em conjunto com a tomada de consciência dos alunos sobre o ritmo da fala. 


\section{Desenvolvimento da pesquisa}

O presente artigo teve por objetivo investigar os procedimentos utilizados pelos professores e livros didáticos de língua portuguesa no ensino de gramática do ensino fundamental, em particular, em relação ao conteúdo de acentuação gráfica e tonicidade. A amostra da pesquisa foi constituída por dois professores do ensino fundamental - um de 4. e um de 5. " série de uma escola pública de Maringá-PR - selecionados a partir de seu aceite em participar da pesquisa.

Tomando como referência Lüdke e André (1986), para atingir os objetivos da pesquisa, optou-se por uma abordagem qualitativa dos dados considerada a mais adequada para a compreensão da dinâmica presente no ambiente escolar. Os dados foram coletados por meio de dois instrumentos: observações de aulas de gramática e análises de livros didáticos. Foram observadas as aulas que abordaram o tema tonicidade e acentuação gráfica, critério que definiu a quantidade de horas de observação em cada série ( 4 . $^{\mathrm{a}}$ série quatro horas e meia e 5. ${ }^{\text {a }}$ série, duas horas). As observações contemplaram o desenvolvimento das atividades: apresentação do conteúdo, exercícios, uso do livro didático e outros materiais, avaliação do conteúdo. Os livros didáticos foram analisados quanto aos procedimentos subjacentes à apresentação e exercício do conteúdo.

\section{Apresentação e discussão dos resultados}

Para a análise, foi utilizado o livro da coleção A Escola é Nossa, de Márcia Paganini Cavéquia (2004) - 4." série. O volume é composto por sete unidades subdividas em oito tópicos entre eles Pensando sobre a língua e Caderno de Ortografia, únicos em que são encontrados os conteúdos investigados - acentuação gráfica e tonicidade.

Em relação à segunda etapa do ensino fundamental foi analisado o livro de 5. série da coleção Ler, entender e criar, de Maria das Graças Vieira e Regina Figueiredo (2004). Nesta coleção cada volume é composto por dez unidades subdividas em sete tópicos. Os conteúdos de acentuação gráfica e tonicidade estão presentes no tópico Veja como se escreve.

O livro didático da 4. série apresenta o conceito de sílaba tônica, classificação das palavras e regras de acentuação somente no Caderno de atividades de acentuação e ortografia, parte do Caderno de Ortografia. As explicações e os exercícios propostos apresentam os dois conteúdos de forma desvinculada. Para introduzir o conceito de sílaba tônica, o livro solicita que o aluno pronuncie várias vezes a palavra menina e indique a sílaba mais forte. Logo após, apresenta 
o conceito gramatical e exemplifica a classificação das palavras, conforme a posição da sílaba mais forte: oxítonas, paroxítonas e proparoxítonas.

Ao explicar a acentuação gráfica de palavras oxítonas, apresenta várias palavras como amor, cipó, calor, funil e José, com o intuito de demonstrar que nem todas essas palavras são acentuadas e que para fazê-lo corretamente devese observar sua terminação. O exercício denominado Complete solicitado para treinar esses conteúdos parece induzir os alunos à observação da terminação de cada vocábulo descartando a identificação da sílaba tônica.

Em outro exercício, é solicitado ao aluno que justifique o porquê da presença ou ausência do acento gráfico em um conjunto de palavras oxítonas. Segundo as orientações fornecidas ao professor, são consideradas corretas somente as respostas que explicam a acentuação a partir de regras de acentuação. Esse tipo de abordagem faz com que os alunos tomem como verdade a ideia de que o acento gráfico aparece somente em vocábulos nos quais tem uma sílaba mais forte e, assim, deixa de dar a ênfase necessária ao fato de que o acento solicitado é o gráfico. Com esse procedimento, não fica claro para os alunos que independentemente de sua grafia toda palavra possui uma sílaba tônica, com exceção dos monossílabos átonos.

Com relação à acentuação das palavras paroxítonas e proparoxítonas, o livro apresenta somente um quadro com palavras deste tipo acentuadas graficamente. Sobre esse tema são apresentados dois exercícios: o primeiro solicita a acentuação gráfica de vocábulos e sua transcrição no caderno por ordem alfabética; o segundo solicita a busca de palavras paroxítonas e proparoxítonas em jornais e revistas. Somente dois exercícios do livro sugerem a relação entre os conceitos de tonicidade e acentuação gráfica. Nesses exercícios, é solicitado aos alunos que indiquem ou pintem a sílaba tônica e, por meio das tentativas auditivas exigidas, é favorecida a percepção dos alunos quanto a tonicidade e sua relação com a acentuação gráfica (Figura 1):
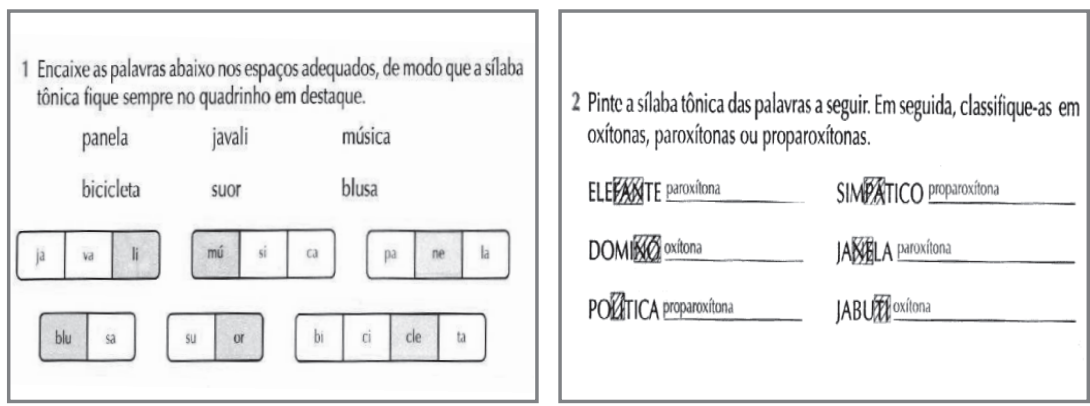

FIGURA 1- EXERCÍCIOS DE IDENTIFICAÇÃO DA SÍLABA TÔNICA DO LIVRO DIDÁTICO DE 4. SÉRIE 
O livro didático da 5. "série aborda os conteúdos tonicidade e regras de acentuação gráfica no tópico Veja como se escreve. Nas unidades anteriores, o direcionamento gramatical vinculou-se diretamente à escrita de determinados vocábulos envolvendo aspectos relativos aos dígrafos. Nesta unidade, quando apresentadas, as questões de acentuação são relacionadas à separação silábica dos vocábulos. Para a realização do exercício, é necessário que os alunos retornem ao tópico Outra leitura, pois a tarefa refere-se a um texto contido neste item no qual é solicitado que sejam grifadas as sílabas mais fortes das duas palavras que compõem o seu título: Atrás do gato. Nessa atividade, é desconsiderado o monossílabo "do" por meio do qual poderiam ser resgatados os conceitos estudados anteriormente integrando-os à atividade presente.

Depois do primeiro exercício, o livro apresenta a diferença entre sílabas tônicas e átonas, bem como a classificação das palavras conforme a posição da sílaba tônica. Apresenta como exemplos, vocábulos com e sem acento gráfico, Bidu, gato e amigo. Tais exemplos podem ser considerados importantes para o aprendizado, em favor da independência existente entre sílaba tônica e acento gráfico. Isto facilita a percepção do aluno sobre as convenções da língua portuguesa, como o caso dos acordos ortográficos.

Para a introdução da acentuação gráfica de palavras oxítonas são apresentados dezesseis vocábulos com e sem acento gráfico, dos quais se solicita leitura em voz alta para identificação auditiva quanto a sua sílaba tônica. Depois desta etapa, os alunos devem identificar a sílaba tônica e sua classificação. O último exercício relaciona a acentuação gráfica à terminação dos vocábulos oxítonos com o objetivo de que os alunos associem esses dois elementos e elaborem uma regra gramatical apresentada em um quadro logo abaixo.

Depois de apresentadas as regras ortográficas, solicita-se que os alunos encontrem cinco palavras oxítonas que recebam acento gráfico e, logo em seguida, elaborem frases. A elaboração de frases permite aos alunos a percepção de que o vocábulo permanece com acento gráfico independente da localização sonora que ele assume em uma frase. No último exercício é solicitada a busca em jornais e revistas dos vocábulos ensinados, reproduzindo os exercícios apresentados nos livros didáticos do primeiro ciclo.

Os vocábulos paroxítonos são abordados na sétima unidade do livro, os vocábulos oxítonos, sexta unidade e proparoxítonos na oitava unidade. Essa fragmentação de conteúdos afins, segundo a literatura, não permite que os alunos percebam as relações existentes entre os temas. Além disso, nos três casos, a classificação é apresentada no item Veja como se escreve, embora o tema relacionado à sílaba tônica se refira a um aspecto próprio da oralidade, enquanto a acentuação gráfica trata de um aspecto da língua escrita. Neste exercício novamente é solicitada a separação de sílabas antes da classificação dos vocábulos. 
A única mudança em relação às atividades propostas para as palavras oxítonas é tão somente a posição das sílabas tônicas. Em outro exercício é solicitada a decisão do aluno sobre a necessidade ou não de acentuação gráfica estabelecendo uma relação direta entre tonicidade e acento gráfico.

Quanto aos vocábulos proparoxítonos sua apresentação ocorre, como nas outras unidades, no tópico Veja como se escreve da oitava unidade do livro. A classificação é abordada por meio de três exercícios estruturalmente iguais: em um deles é apresentada a regra gramatical de acentuação das palavras proparoxítonas sem justificar o porquê desta norma; no último exercício sobre classificação e acentuação gráfica é sugerida uma atividade em grupo para a revisão do conteúdo gramatical das unidades anteriores. Seu foco são os vocábulos acentuados graficamente e desconsidera as palavras que não possuem acento gráfico, embora sejam submetidas às mesmas regras.

A comparação entre os dois livros didáticos mostra que no de $4 .^{a}$ série o conteúdo é apresentado de forma integrada e o de 5. série tende a sua fragmentação. No primeiro manual, primeiramente, é abordado o conceito de sílaba tônica e, posteriormente, são apresentadas as regras de acentuação gráfica para a resolução dos exercícios. Este tipo de procedimento parece ser mais adequado ao desenvolvimento do tema, pois leva o aluno a compreender que quase todos os vocábulos possuem uma sílaba tônica e que somente alguns são grafados devido à vigência ortográfica da norma. $\mathrm{O}$ livro direcionado à segunda etapa do ensino fundamental aborda o conteúdo de acentuação em unidades distintas, revisadas em conjunto somente no tópico final. Nessas situações são priorizados os vocábulos acentuados graficamente e a estrutura dos exercícios mantém-se relacionada à classificação das palavras quanto à sua tonicidade.

Apesar das diferenças, o modo como os dois livros didáticos apresentam o conteúdo sobre tonicidade e regras de acentuação favorece o estabelecimento de confusão conceitual por parte de alunos e professores, pois não mostra que a sílaba tônica é um aspecto presente na fala e as regras de acentuação na escrita. Marcando a importância dessa distinção, assinala que não diferenciar esses dois aspectos limita o processo de instrumentalização linguística dos alunos.

\section{Quanto às observações de aulas}

Comparando os dados das observações com as propostas dos Parâmetros Curriculares Nacionais (BRASIL, 1997) sobre o ensino de ortografia, pode-se afirmar que a professora de $4 .^{\mathrm{a}}$ série manifesta uma postura pedagógica distanciada desses documentos e similar aos pressupostos teórico-metodológicos da Pedagogia Tecnicista, cujo foco é o livro didático. Do tempo total da aula, $43 \%$ (115 min.) foram dedicados à resolução de exercícios do livro didático e 
49\% (130 min.) à correção desses exercícios no quadro de giz. Além disso, a professora de $4 .^{\text {a }}$ série não fez uso do tempo das aulas observadas para expor e explicar oralmente o conteúdo gramatical (Gráfico 1).

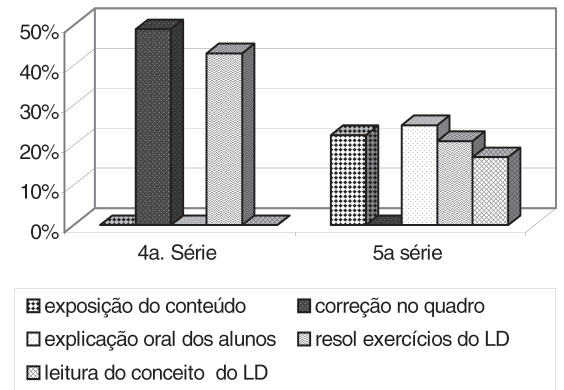

GRÁFICO 1- A PRÁTICA PEDAGÓGICA DOS PROFESSORES DE 4. ${ }^{\mathrm{a}}$ E 5. ${ }^{\mathrm{a}}$ SÉRIES DO ENSINO FUNDAMENTAL

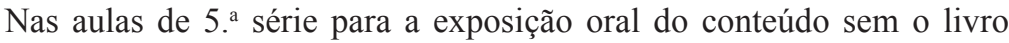
didático, o professor fez uso de 23\% (27 min.) do tempo de aula, 25\% (30 min.) para retomada oral deste tema por parte dos alunos, 20\% (25 min.) para a resolução de exercícios dos livros didáticos e 17\% (20 min.) para retomada do conteúdo por meio do livro didático. Nas aulas observadas, em média de 13\% (13 min.) do tempo da aula foram usados para recados, brincadeiras, enquanto a cópia de exercícios do quadro de giz, 2\% (3 min). Este professor não corrigiu exercícios no quadro de giz, utilizando-se de outros recursos para o ensino do conteúdo em foco.

As observações de aula mostraram que os dois professores investigados - a professora da 4. ${ }^{\mathrm{a}}$ série e o professor da 5 . $^{\mathrm{a}}$ série - utilizaram como recurso básico de ensino o livro didático. A conduta dos entrevistados mostra-se consistente com as considerações de Silva (1996, p. 13), segundo as quais o desempenho insatisfatório dos alunos pode estar vinculado ao uso do livro didático no direcionamento da atuação pedagógica dos professores. Para o autor, esse comportamento pode levar os professores a uma "anemia cognitiva" e ao rebaixamento da qualidade de seu trabalho.

Além dos prejuízos causados pelo uso quase exclusivo do livro didático, é importante ressaltar que o pouco tempo de exposição do conteúdo para os alunos, como constatado nas observações realizadas na turma de 4 . $^{a}$ série, favorece uma aprendizagem insatisfatória dos conteúdos. Segundo Dorneles (1987), a redução do tempo de aula para a realização desse tipo de atividade é considerada um dos mecanismos seletivos da escola. Isto significa que aos sujeitos que têm menos condições de saber ou aprender o conteúdo escolar em 
outras situações são privadas as oportunidades necessárias à aprendizagem na instituição designada socialmente para tanto. Em outros termos, pode-se dizer que a escola não está cumprindo seu papel de transmissor do saber escolar científico a todos os cidadãos de forma equitativa.

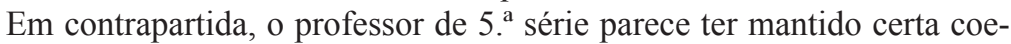
rência na distribuição do tempo de desenvolvimento das quatro categorias de atividades - exposição oral, resolução de exercícios do livro didático, resolução de exercícios no quadro e leitura do conceito gramatical que o livro didático apresenta (Gráfico 1). Observa-se que nenhum dos dois professores apresentou a acentuação gráfica como uma norma convencionada pelo conjunto social. Segundo Morais (2002), se abordado desta maneira, os alunos poderiam compreender que certos conteúdos são apenas convenções temporárias e arbitrárias que precisam ser memorizadas e conscientizadas para aquisição de uma melhor competência na linguagem oral, leitura e escrita.

Estudos anteriores como os de Cagliari (1986) e Morais (2002) enfatizam que é na 4. a e 5. séries do ensino fundamental o momento mais apropriado para a abordagem do conceito de sílaba tônica e acentuação gráfica, pois às séries seguintes restaria o encargo de retomar esse conteúdo apenas quando necessário, dedicando-se ao desenvolvimento de outros conceitos gramaticais.

\section{Considerações finais}

No conjunto dos livros investigados constatou-se que a classificação das palavras em oxítona, paroxítona e proparoxítona é determinada somente pela posição da sílaba tônica, enquanto as regras ortográficas são apresentadas sem diferenciação dos aspectos relativos à fala e à escrita.

O livro didático da $4 .{ }^{a}$ série apresenta o conteúdo no tópico concernente ao ensino de ortografia. Retoma o ensino da sílaba tônica e traz pelo menos dois exercícios que promovem a reflexão do aluno quanto à posição da tonicidade dos vocábulos, independente da acentuação gráfica, sob a qual se enquadram nas regras ortográficas. Mas esta apresentação do conteúdo é neutralizada no momento em que são expostas as regras gramaticais. Nesta exposição, o livro didático desconsidera totalmente a tonicidade, e a acentuação gráfica é justificada tão somente pelas regras sem que haja uma explicação das convenções sociais. No livro de 5. ${ }^{a}$ série, o conteúdo é abordado em unidades isoladas, e justificado somente pelas regras de acentuação que prioriza os vocábulos que possuem acento gráfico. 
Os dados evidenciam que o conteúdo de acentuação gráfica é apresentado nos livros didáticos, e desenvolvido pelos professores a partir de uma abordagem pedagógica tecnicista. Apesar das orientações aos professores e das referências bibliográficas desses manuais apresentarem propostas de ensino ditas inovadoras e baseadas nos PCNs, verificou-se que os conceitos e exercícios de acentuação gráfica e tonicidade são abordados de forma isolada. Os dois conteúdos não são considerados em suas afinidades e particularidades, evidenciando um enfoque reducionista, cristalizado e incapaz de promover a reflexão dos alunos sobre a diferença entre a língua falada e a língua escrita. Tanto nos livros didáticos como nas atuações dos professores analisados, as novas teorias linguísticas e suas propostas de ensino não se mostram presentes, justificando a confusão conceitual transmitida aos alunos.

Embora o livro didático devesse exercer uma função mediadora entre o conhecimento científico escolar e os conhecimentos prévios dos alunos, em relação ao conteúdo de tonicidade e acentuação gráfica os manuais analisados acabaram por simplificar e distorcer esses conceitos. Por conseguinte, no processo de transposição didática, os professores reproduziram a confusão conceitual estabelecida pelos livros. Os dados sugerem que os livros didáticos não estão apresentando os conceitos escolares de forma satisfatória e, portanto, não deveriam continuar sendo considerados como referencial principal e, até mesmo único, para o ensino de conteúdos gramaticais como os focalizados nesta pesquisa.

Além disso, conforme constatado nas observações de aula, o tempo reduzido para exposição e explicação do conteúdo e a resolução dos exercícios a partir da separação silábica das palavras contribuem para a manutenção da confusão conceitual apresentada pelos livros didáticos. Os dados revelam o desenvolvimento de uma abordagem didática que prioriza o ensino de algoritmos gramaticais e não a aprendizagem dos conceitos envolvidos na tarefa de identificação da sílaba tônica. Com base nesse processo de ensino, os alunos não podem vir a tomar consciência e, muito menos, memorizar as regras gramaticais para a elaboração da escrita, pois ora as entendem como um aspecto dependente da fala, ora como regra social.

Os resultados sugerem que a escola, representada pelos professores e livros didáticos, não está favorecendo a formação de conceitos no ensino de tonicidade ou a tomada de consciência das regras de acentuação gráfica. Por essa razão, considera-se relevante a organização e experimentação de novas formas de ensinar esses conceitos de maneira a levar em conta seus aspectos comuns e, principalmente, suas diferenças - prosódia e regras da língua materna, além da não dependência do livro didático. Esses aspectos são relevantes, visto que a função do professor de língua materna é a de promover a competência 
comunicativa dos alunos, ou seja, a articulação de seus saberes linguísticos e não sua redução conceitual.

\section{REFERÊNCIAS}

ARNAY, J. Reflexões para um debate sobre a construção do conhecimento na escola: rumo a uma cultura científica escolar. In: RODRIGO, J. M.; ARNAY, J. Conhecimento cotidiano, escolar e cientifico: representação e mudança. 2. ed. São Paulo: Editora Ática, 1999.

BATISTA, A. A. G. Aula de Português: discurso e saberes escolares. São Paulo: Martins Fontes, 1997.

BEGER, M. Educação e dependência. Porto Alegre: Difel, 1976. p. 269-290.

BOGDAN, R.; BIKLEN, S. Investigação qualitativa em educação: uma introdução à teoria e aos métodos. Porto: Porto Editora, 1999.

BORBA, F. da S. Introdução aos estudos lingüísticos. 4. ed. São Paulo: Editora Nacional, 1975.

BRASIL. Secretaria de Educação Fundamental. Parâmetros curriculares nacionais: Língua Portuguesa. Brasília-DF: MEC/SEF, 1998.

CAGLIARI. L.C. Alfabetização \& Lingüistica. 10. ed. São Paulo: Scipione, 2002. p. 86-93.

. Ortografia na escola e na vida. In: SECRETARIA de Educação do Estado de São Paulo. Isso se aprende com o Ciclo Básico. São Paulo: CENP, 1986.

CALSA, G. C. Intervenção psicopedagógica e problemas aritméticos no ensino fundamental. Tese (Doutorado) - Unicamp, Campinas, 2002.

CÂMARA JUNIOR, J. M. Manual de expressão oral \& escrita. 22. ed. Petrópolis: Vozes, 2002.

. Para o estudo da fonêmica portuguesa. 2. ed. Rio de Janeiro: Padrão, 1970.

CAVÉQuiA, M. P. A Escola é Nossa. São Paulo: Scipione, 2004. Português: 4. ${ }^{\mathrm{a}}$ série.

CEZAR, K. P. L.; CALSA, G. C; ROMUALDO, E. C. Intervenção Pedagógica sobre acentuação gráfica no ensino fundamental. Relatório Final de Iniciação Científica. Maringá, 2006. 
DORNELES, B. V. Mecanismos seletivos da escola pública: um estudo etnográfico. In: LIMA, B. J. Psicopedagogia o caráter interdisciplinar na formação e atuação profissional. Porto Alegre: Artes médicas, 1987.

GUIRAlDELli JUNIOR, P. O que é Pedagogia. 6. ed. São Paulo: Brasiliense, 1991.

INEP/INSTITUTO NACIONAL DE ESTUDOS E PESQUISAS EDUCACIONAIS. Informe de resultados do SAEB 1995, 1997 e 1999. Brasília-DF: Ministério da Educação, 2002.

LACASA, P. Construir conhecimentos: um salto entre o científico e o cotidiano? In: RODRIGO, J. M.; ARNAY, J. Conhecimento cotidiano, escolar e cientifico: representação e mudança. 2. ed. São Paulo: Editora Ática, 1999.

LAJOLO, M. Livro didático: um (quase) manual de usuário. Em Aberto, n. 69, p. 2-9, 1996.

LÜDKE, M.; ANDRÉ, M. E. D. A. Pesquisa em Educação: abordagens qualitativas. São Paulo: EPU, 1986.

MACHADO, N. J. Sobre livros didáticos: quatro pontos. Em Aberto, n. 69, p. 30-38, 1996.

MORAIS, A. G. Ortografia: Ensinar e aprender. 4. ed. São Paulo: Ática, 2002.

POZO, J. I. A aprendizagem e o ensino de fatos e conceitos. In: COLL, C. Os conteúdos na reforma: ensino e aprendizagem de conceitos, procedimentos e atitudes. Porto Alegre: Saraiva, 1998.

SAUSSURE, F. Curso de Lingüistica geral. Tradução de: Antônio Chelini, José P. Paes e Izidoro Blinkstein. 6. ed. São Paulo: Cultrix, 1990. p. $42-74$.

SILVA, E. T. Livro didático: do ritual de passagem à ultrapassagem. Em Aberto, n. 69, p. 11-15, 1996.

SOARES, M. O livro didático como fonte para a história da leitura e da formação do professor-leitor. In: MARINHO, M. Ler e navegar: espaços e percursos da leitura. Campinas: Mercado de Letras/ALB, 2001. p. 31-76.

TRAVAGLIA, L. C. Gramática e Interação: uma proposta para o ensino de gramática no $1 .^{\circ}$ e $2 .^{\circ}$ Graus. São Paulo: Cortez, 1996.

VIEIRA, M. G; FIGUEIREDO, R. Ler, entender e criar. São Paulo: Ática, 2004. Língua Portuguesa: 5. série. 